\title{
The Effect of Twitter in Academic Achievement and Students' Motivation toward Mathematics
}

\author{
Sami M. Alshehri* \\ King Khalid University, Saudi Arabia \\ Received: 20/4/2020 \\ Accepted: $19 / 7 / 2020$
}

\begin{abstract}
The purpose of this quasi-experimental study was to determine the effectiveness of Twitter when used in conjunction with a non-traditional type of educational approach referred to as the "flipped classroom method" upon the academic achievement of 12th grade students and their learning motivation towards mathematics. The study used a quantitative approach, and the sample consisted of 48 students. The study was conducted during a three-week period in two public high schools in Abha, Saudi Arabia. The first hypothesis was that the use of Twitter would improve academic performance in mathematics. The second hypothesis was that learning in a flipped classroom via Twitter would lead to an improvement in math performance but that this improvement within the flipped classroom would differ across gender. The third hypothesis was that learning in a flipped classroom via Twitter would lead to more positive attitudes towards mathematics. The findings did not support the first or the second hypotheses; when used in the context of a flipped classroom approach, Twitter, did not improve academic achievement: $F(1,46)=$ $.49, \mathrm{p}=.486$. Improvement in academic achievement from pretest to posttest also did not differ across gender; $\mathrm{F}(1,44)=.00, \mathrm{p}=.963$. However, the results did support the third hypothesis; within the flipped classroom, the improvement in motivation was stronger for girls than it was for boys; $\mathrm{F}(1,22)=51.32, \mathrm{p}<.001$.
\end{abstract}

Keywords: Twitter, flipped classroom, academic achievement, learning motivation.

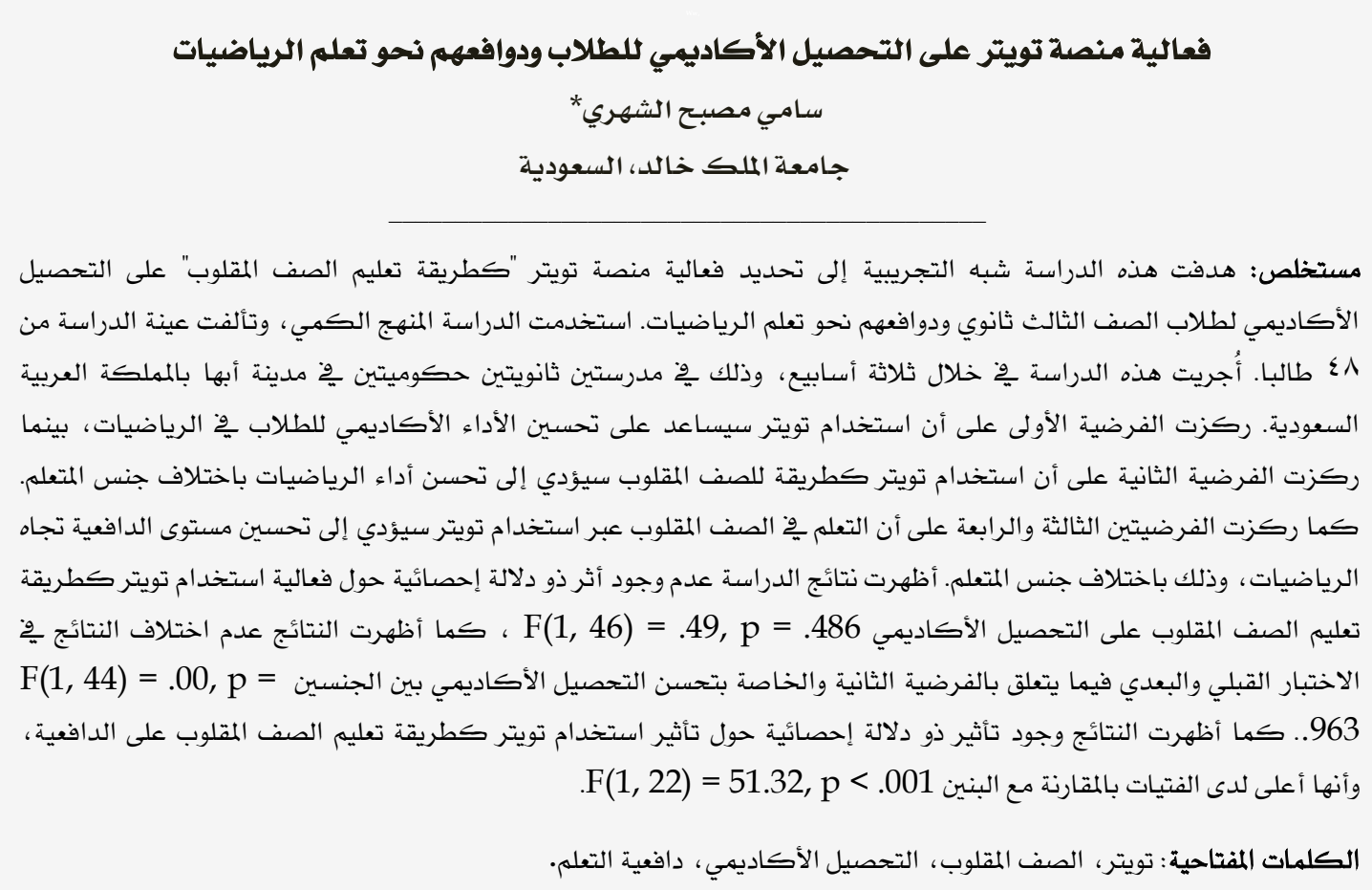

*smshehrie@kku.edu.sa 
The changing circumstances of teaching and learning is a major feature of this era, especially with accelerated changes in educational technology and its applications. Advancing technology and the rapid adoption of mobile devices have reshaped daily life and the connections between people through continuing interactions of children, youth, and adults with such technology. This situation has many educators to seek new instructional methods to meet the requirements of the learning environment by merging technologies and student collaboration. One reason this is being done is as part of an effort to increase student academic achievement in mathematics (Archambault, Wetzel, Foulger, \& Williams, 2010). In order to assess the quality of instructional results and their suitability for contemporary requirements as well as future goals, there is a need to review the educational ideologies, systems, and practices that have been implemented in the past (Unakorn \& Klongkratoke, 2015). Therefore, it is important to evaluate the merging modern instructional methods. Such an evaluation is necessary so that educational institutions will be able to invert traditional classrooms via micro-blogging sites such as Twitter, to keep pace with society in general and to interact with students in particular (Almankory, 2019; Anderson, 2011).

Twitter is one of the most popular microblogging interaction sites around the world. It has recently become a common part of daily activities for most people, regardless of their race, religion, nationality, or other demographic characteristics (Yakin \& Tinmaz, 2013). In addition, Twitter is one of the most powerful tools for conveying messages, and it influence has been greatly amplified in the recent years (Vilchez, 2016). In Saudi Arabia, 40\% of Internet users have Twitter accounts. This amounts to approximately 2.4 million Twitter users (El Mourad, 2014), and this number is increasing every day. This means that roughly half of Twitter users in the Middle East live in Saudi Arabia, (Abdurabb, 2014). Furthermore, Zickuhr and Rainie (2014) reports that 91\% of high school students between 16-17 years old are users of social networking, and that
$50 \%$ of them use Twitter quite frequently. However, the number of Internet users and active social media accounts has been rapidly increasing each year in Saudi Arabia. By the middle of 2018, the number of internet users in Saudi Arabia had risen to 30.25 million, which is approximately $91 \%$ of the population. During this same time period, the active social media accounts in the country had risen to about 25 million, which is approximately $75.19 \%$ of the population (Global Media Insight (GMI), 2018). In addition, $52 \%$ of Saudi Internet users have Twitter accounts, (approximately 17.3 million Twitter users), and most of them are between the ages of 15 and45 years old (GMI). Furthermore, when Twitter is used in the learning process, it is possible to increase the level of student engagement, and mobilize them to actively participate in the instructional process (Junco, Helbergert, \& Loken, 2010).

On the other hand, the global trends toward the greater use of the "flipped classroom method increases with each passing year. The flipped classroom method is an alternative educational approach which requires the students to examine, discuss, and work with the course material prior to attending the formal class presentation of the material, during which the instructor discusses and elaborates upon the material, thus inverting the convention sequence of information presentation. James (2014) indicated that, when a search was conducted using the Google engine, there were approximately 8 million blogs related to flipped classroom, while there were 2,740 blogs for the same concept which were found when a search was conducted using Google Scholar. However, in April of 2020, Studyers found about 20.8 million blogs when a search was conducted using the Google search engine to search for mentions of the term "flipped classrooms," while 89,800 blogs were found when conducted as search using that same term with Google Scholar. This indicates the number has dramatically increased during the last five years.

The teaching of statistics and probability theory and its applications have seen unparalleled growth in high school mathe- 
matics course in Saudi Arabia during the past two decades. Such courses have been included in the mathematics content as a part of high school curriculum standards that in which students must demonstrate proficiency. This is because of the usefulness of this subject in daily life, which supports probabilistic reasoning, and its essential role in other disciplines and professions (Batanero \& Borovcnik, 2016; Jones, 2005). The current trend in high school mathematics content in Saudi Arabia is focused upon teaching students to explore data, formulate questions, sampling and experimentation, simulations, specifying methods to collect and analyze data, and providing justifications for the conclusions which are based on data (Asiri, 2018). However, statistics and probability is not easy topics to understand, and many students experience great difficulties when they attempt to learn them. Also, most teachers are finding it difficult to teach such these topics (Batanero \& Díaz, 2012; Ozofor, 2015).

\section{The Flipped Classroom Model}

The flipped classroom is a new instructional strategy in which students are introduced to pre-recorded learning concepts by video, online, or other technological methods outside of the traditional learning environment. After completing the lesson in this preliminary manner, the students come to the class the following day in order to discuss what they have learned with their teacher, while the teacher makes corrections of any mistakes in the knowledge and understanding of the content that the students have watched (Fulton, 2012). Students are expected to complete their homework and discuss the content during the regular classroom time (Bergmann \& Sams, 2012). Thus, it can be said that normal work of school and homework have been reversed, as students are expected to work at home in what they traditionally would do in class, and vice versa.

The role of teacher and student varies according to the method used in the learning process. In traditional learning style, learning is completely focused on a teacher, who provides a variety of information and experiences, while student remains silent during most of the class time. In a flipped classroom situation, the role of the teacher becomes quite different. In a flipped classroom, the learning process is centered on the learner and their effectiveness and interaction with the instructional content. In contrast, the teacher becomes a guide and facilitator of the learning process, as well as an innovator of fun activities which are appropriate to the level of students (Bergmann \& Sams, 2012). This flipped classroom method gives students more time to examine the instructional material when they are out of school. This inverted pattern is reported to contribute to mastery of learning, increased collaboration, self-confidence, and the opportunity to direct the observations and criticism of students about scientific content (Unakorn \& Klongkratoke, 2015).

Flipped classrooms have specific characteristics, as do other instructional methods, that must be applied proper in order to be effective and useful. Hamdan et al. (2013) stated that effective and efficient implementation of the flipped classroom requires the availability of four main pillars. These four pillars are: (a) a flexible learning environment that allow teachers to reorganize the classroom as needed; (b) a learning culture that allows students to be the center of learning and producers of knowledge; (c) intentional content that is defined by teachers and discovered by students; and (d) a professional educator who possesses and has developed skills to use the flipped classroom method professionally. However, Yarbro, Arfstrom, McKnight, and McKnight (2014) have added eleven indicators to the previous four pillars that all educators must incorporate well into their practice. These eleven indicators include: (a) establishing spaces and time frames, (b) monitoring students, (c) learning mastery, (d) engaging in meaningful activities, differentiation and feedback, (e) prioritizing concepts, (f) creating or curating relevant content, $(\mathrm{g})$ content accessibility, (h) teacher availability, (i) formative assessment, and (j) collaboration with other teachers (Yarbro et al., 2014). 
The flipped classroom method is reported to work well at the high school level. Examining the instructional content before the time of the lesson allows students to deeply discuss and practice enrichment activities in class (Pearson, 2013). In the last five years, a number of studies conducted in Saudi Arabia have indicated the success of using the flipped classroom approach at the high school level, where the characteristics and level of age of learners are appropriate to apply technology in education (Abo Galbh, 2015; Aldaosary \& Al-masaad, 2017; Al-harbi, 2017). Stone (2012) and Harris and Rea (2009) have summarized the advantages of utilizing the flipped classroom method in an educational context. These advantages include: (a) encouraging students to become lifelong learners by developing their skills in acquiring knowledge and dealing with technology, (b) increasing interaction with the subject through active learning, (c) increasing interaction between students and teachers through dialogue and discussion during work activities within the classroom.

\section{Twitter as an Instructional Tool}

Twitter is a type of micro-blogging website that was established on 2006, and allows users to post messages of a maximum of 280 characters to the audience. Once a member signs up on Twitter, he/she is able to follow other users and vice versa. In Twitter, users are able to send tweets, make retweets, replay to tweets, use the @ sign to mark others, send messages directly to others, send private messages, and make your own list of users (Yakin \& Tinmaz, 2013). Twitter is a popular site because it keeps members updated with news of events happening around them and its relative ease of sharing posts publically. Twitter seem to fulfill a human need to communicate with others, and offers the ability to act as voyeur to other active bloggers and passive readers (Kaplan \& Haenlein, 2010). In addition, Twitter creates social networks between teachers and students, which add educational value and alternative ways for communication and participation (Minocha, Schroeder, \& Schneider, 2010).
Some authors have reported that twitter can be a great adjunct to the learning process when applied to educational content. This is because it is an unconventional tool, and has the potential to pique the interest of students (Buzzelli et al., 2019; Vilchez, 2016). In addition, students and teachers can communicate via Twitter almost instantly by writing their thoughts, questions, or answers using messages composed of 280 characters or less (Dunlap \& Lowenthal, 2009; Vilchez, 2016). Furthermore, Twitter offers opportunity for Studyers to conduct academic studies in multiple fields. There are many Study opportunities for educational aims that are still emerging about how to use Twitter effectively in an education context (Fox \&Varadarajan, 2011). It may be useful to examine the integration of Twitter into the learning context through classroom activities (Galagan, 2009). Many studies have been conducted on the use of Twitter in higher education, but there has been a lack of Study focused on instructional use of Twitter for mathematics courses in high school settings.

Twitter may help increase the level of academic achievement for high school students. Blessing et al. (2012) and Junco et al. (2010) have reported that Twitter has a significantly positive effect on student grades as well as student engagement in the learning context. Also, Van Vooren and Bess (2013) reported that Twitter supports the performance of students on standardized tests, and there is a correlation between the use of Twitter and student achievement. Conversely, Vilchez (2016) reported that using Twitter in a learning environment did not increase the academic achievement for 9th grade students in Algebra 1, (specifically with regards to the linear equations unit), even though the use of Twitter did increase the level of student motivation.

One other benefit that Twitter has been claimed to provide is that it may enhance the social skills and presence in an online learning context. Dunlap and Lowenthal (2009), Fox and Varadarajan (2011), and Junco et al. (2010) each reported that Twitter offers several benefits. These benefits include all of the following: (a) giving 
quick help for the problems of learners; encouraging class participation and discussion; (c) improving writing skills for learners; (d) facilitating student interaction; (e) obtaining respect from others; (f) helping learners to engage into a community of practice; (g) supporting selfdirected and independent learning via participating in informal learning activities; and (h) permitting the formation of relationships during the class as well as the continuation of such relationships after the class ends. In addition, Twitter may also improve other behavioral aspects as well, including: (a) self-regulation, (b) online and in-class attendance, (c) persistence, (d) adherence to the instructional rules, (e) student feelings toward school, (f) enjoyment of the instructional activities, and $(\mathrm{g})$ increasing parental support for learning (Buzzelli et al., 2019; Fredricks et al., 2011).

Twitter reportedly helps to prevent and diminish student feelings of isolation when learning in or out of the classroom. This may be because Twitter supports studentengagement in learning, which may also enable them to overcome the feelings of isolation (Carpenter \& Krutka, 2014; Evans, 2017). Also, when the teacher responds in a timely manner to student emails, phone calls, or messages, this may may diminish or prevent them from feeling a sense of isolation (Wei, Chen, \& Kinshuk, 2012). However, the instructions that teachers would use can offer a high level of social presence, which, in turn, may prevent feelings of isolation when a lack of communication is frequent within the learning environment (Dunlap \& Lowenthal, 2009). This may be because Twitter provides immediate communication between instructor and students, as well as between the students themselves. Such instant communication may occur not merely during regular school hours, but at any time of the day or night (Junco et al., 2012).

However, there are also some possible drawbacks of Twitter that must be taken into consideration when it is used in instructional situations. Isolation is an issue that students may confront when teachers do not respond to their queries and questions (Evans, 2017). Students feel isolated when they send tweets out, but do not receive any response or feedback from the instructor or classmates (Nicholson \& Galguera, 2013). The study of Pyhailto; Toom, Stubb, and Lonka (2012) constructed a survey that consisted of 81 questions to examine the effect of isolation on the well-being of students. The results revealed that isolation frequently leads to a low sense of wellbeing among students. In addition, students are sometimes distracted or overwhelmed when using Twitter (Fox \& Varadarajan, 2011). In addition to this, there are numerous other issues that must be considered when using Twitter in learning context. These issues include all of the following: (a) workload issues for both teachers and students, (b) lack of real social interactions among students; (c) limited trust in peer feedback, (d) the inability to assess the learning activities, (e) the right of content ownership, (f) lack of willingness to use Twitter, (g) presentation of inappropriate content, and (h) the lack of experience with using Twitter (Schroeder et al., 2010).

\section{Problem of statement}

The use of social media has become daily practice for students, which has shifted their learning and communication habits. However, while the used of social network sites have increased, the educational field is definitely in need further examining the intersection and interaction of Twitter and mathematics learning. According to Alhamadi (2017) "the social media influence on Saudi students is an area that needs to be studied because the field of educational technology in the KSA is lacking such studies" (p. 29). After reviewing the literature, I have found that there were a few studies that investigated the use of Twitter in high school mathematics classes (Gao et al., 2012; Junco et al., 2011; Vilchez, 2016; Vohra, 2016). This seems to be because the use of Twitter in educational settings has mostly been limited to higher education rather than in K-12 settings. In addition, most of the literature has used a descriptive approach instead of the experimental approach (Vilchez, 2016). Thus, 
this present study was primarily intended to fill the gap in the literature related to the use of Twitter in mathematics education in high school. In addition, it is hoped that this study might open the door to future studies about Twitter use in mathematics education and other secondary education fields.

Students are still struggling to be successful in statistics and probability classes. The annual report by National Center for Assessment (formally known, QIYAS) (2019) reported that only $57 \%$ of 12 th grade students in Saudi Arabia have passed the examination for the section on data analysis. This means that more than one-third of Saudi 12th grade students have not able to acquire the key concepts of statistics and probability. Also, students often feel that statistics is difficult, irrelevant to reality, and has no meaning in their lives (Carnell, 2008). However, the shortcomings of a student in statistics and probability will have serious consequences for the future academic career of sudents (Batanero \& Borovcnik, 2016). Thus, this study was conducted because the serious need for students to develop their mathematical performance in statistics and probability. The use of Twitter may provide a good instructional tool for students which will help them to learn statistics and probability. In addition, the results of this study might make significant contributions to the understanding of how Twitter affects high schools students learning statistics and probability, as well as high school students studying other subjects.

\section{Study objective}

This study was focused on the effectiveness of using Twitter as a flipped classroom method upon the academic achievement of 12th grade students and upon their learning motivations with regards to mathematics.

\section{Study questions}

The following Study questions that were examined in this study:

1. When used in the context of a flipped classroom, does Twitter increase the academic achievement for 12 th grade students in mathematics?
2. When used in the context of a flipped classroom, does Twitter increase the learning motivations for 12 th grade students in mathematics?

3. Are there gender differences in the academic achievement of students when they are taught using traditional methods compared to when they are taught using Twitter in the context of a flipped classroom?

4. Are there gender differences the learning motivations of students regarding mathematics when they are taught using traditional methods compared to when they are taught using Twitter as in the context of a flipped classroom?

\section{Study hypotheses}

1. It was hypothesized that learning in a flipped classroom via Twitter, versus learning in a traditional classroom, would lead to an improvement in math performance.

2. It was hypothesized that learning in a flipped classroom via Twitter would lead to an improvement in math performance but that this improvement within the flipped classroom would differ across gender.

3. It was hypothesized that learning in a flipped classroom would lead to more positive attitudes towards mathematics.

4. It was hypothesized that learning in a flipped classroom via Twitter would lead to more positive attitudes towards mathematics but that this improvement within the flipped classroom would differ across gender.

\section{Methodology}

The purpose of this study was to examine the effects of Twitter when used in the context of a flipped classroom method compared with the traditional method of mathematics instruction. This was done in order to determine whether the use of Twitter would enhance the academic achievement of 12th grade students and/or their learning motivation toward mathematics. The study focused on a statistics and probability unit, and was con- 
ducted in two public high schools in the southern region, Saudi Arabia (Abha City). The design was quasi-experimental (Campbell \& Stanley, 1963), with a nonequivalent control group. Such a Study design is considered a suitable alternative to an experimental design when randomization is not possible (Gall, Gall \& Borg, 2006). The academic achievement and learning motivations of the students in both the experimental and the control groups toward mathematics was measured sequentially, based upon the test and survey which was constructed by the Studyer.

\section{Study design and procedure}

The Study design for this study was the non-equivalent control group design. Two comparable groups were chosen that were as similar as possible to provide the fairest comparison. The experimental groups used the Twitter as a flipped classroom method, while the control groups were only taught through traditional instruction methods (Table 1). Both groups completed the Probability and Statistics pre-test and motivational survey. At the end of the study, both groups completed the Probability and Statistics post-test and motivational survey. The post-test scores of the students were compared across groups, controlling for pre-test scores using statistical analysis. In addition to this, a training session about how to use Twitter as a flipped classroom method was provided to the math teacher and students who had previously agreed to participate in the study. The training was completed in one day (3 hours), and ensured that the teacher and participants had the instructions and skills for eliminating any kind of validity threats.

In addition, the Studyer created a protected Twitter account for the course
(http://twitter.com/MATH20191), and signed up each participant with a Twitter account, using a pseudonym for the confidentiality. Also, all participants were required to follow the account for the course. Participants were encouraged to practice how to use the features of Twitter, such as tweeting, retreating, mentions, private messages, post pictures, and other relevant tools. Each day, the teacher was required post a topic on the course account outside of the hours when the class was being conducted. After this topic was posted, the participants would tweet in response to the topic by posting their thoughts, writing comments, and asking/answering questions. The next day, the teacher and the students would meet together during the regular class time, discuss the concepts of the lesson, solve problems, and do activities related to the lesson. Participants were free to access their Twitter accounts during class, and the teacher would replied to their inquires, and provide feedback as needed.

Table 1

Nonequivalent Control-Group Design

\begin{tabular}{lccc} 
& Pretest & Treatment & Posttest \\
\hline Experimental & $\mathrm{T}_{1}$ & $\mathrm{X}$ & $\mathrm{T}_{2}$ \\
Control & $\mathrm{T}_{1}$ & & $\mathrm{~T}_{2}$
\end{tabular}

$\mathrm{T}_{1}$ represents the Probability and Statistics test that was used as the pretest.

$X$ represents the experimental treatment. The treatment was the use of Twitter.

$\mathrm{T}_{2}$ represents the Probability and Statistics test that was used as the posttest.

\section{Sampling}

Participants were recruited from the K-12 public high schools in Abha City, located in the southern region of Saudi Arabia. The September 2019 student enrollment data indicated that 745 students were in attendance at the schools. The demographic background of the student population for the 2019-2020 school year consisted of

Table 2

Demographic for the students participating in the study

\begin{tabular}{ccccccc}
\hline School\# & Experimental Group & Control Group & Male & Female & Saudi & Non-Saudi \\
\hline 1 & 0 & 24 & 12 & 12 & 21 & 3 \\
2 & 24 & 0 & 12 & 12 & 22 & 2 \\
Total & 24 & 24 & 24 & 24 & 43 & 5 \\
\hline
\end{tabular}


92.8\% Saudis and $7.2 \%$ Non-Saudis. The total number of 12th grade students was 216 , or approximately $29 \%$ of the student population (Ministry of Education, 2019).

For the purposes of this study, students from two 12-grade mathematics classes were used as the sample for this study (one class for the experimental group and one for the control group). An effort was made to ensure that the two groups were as demographically similar as possible so that any differences could be attributed to the independent variable rather than biases or differences within the sample. The sample of students was comprised of 12th grade students who received traditional instruction in mathematics in regular high school mathematics classrooms during the 2019-2020 school year. The 12th grade classroom setting was been chosen because of the large amount of time spent in direct teacher contact with students. Standard practice in the city where the study took place is for12th grade teachers spend seven hours per day in direct contact with students.

\section{Instrumentations}

Probability and statistics test. The Stud year reviewed the official description of math curriculum for the K-12 grade, and it shows that statistics and probability are introduced in the fifth grade. In the math book for the 12th grade, the topics such as exploring the results obtained from a survey sample and a whole population, cases and survey and experimental studies, measure of central tendency to represent a sample of data, the dispersion metrics, conditional probability, natural probability, probability distribution, and binomial probability are covered. (Ministry of Education, 2019). To assess students in statistics and probability in the experimental and control groups, a general measure of knowledge and skill related to statistics and probability was obtained from all students for use as a possible covariate. However, since no existing test has been judged as an adequate measure of knowledge and skill related to statistics and probability, the pre-test and the posttest were constructed by drawing upon previous Study that used similar topics.
To create the covariate tests, items were either constructed or adapted from one of two sources: (a) tasks used in previous Study studies of statistics and probability (Jacob, 2013; Mohammed, 2012); or (b) from the 12th grade textbook. The test was initially composed of 20 multiple-choice items which aimed to measure the achievement of the students in statistics and probability. In addition, each correct answer was worth one point, and each incorrect answer is worth zero points. In order to obtain an acceptable degree of content validity and face validity, the test was evaluated by six mathematics teachers, each of whom had more than 10 years of experience in teaching mathematics in high school. Feedback from this group of teachers was used to eliminate unneeded or irrelevant items. Based on this revision, four questions were removed Thus, the final copy of the test consisted of 16 multiple-choice questions. In addition, as a measure of reliability, the test was administered to 30 12th grade students in Abha, and the Cronbach's alpha reliability coefficient was found the be 0.81 . This result demonstrates that the test had an acceptable degree of reliability.

Motivational Survey. The participants in both groups completed the motivational survey at the beginning and the end of the study. The purpose of this survey was to measure the level of motivation that students had in learning statistics and probability before and after the treatment. The Studyer has made an extensive review of the relevant literature, such as Ambusaidi and Al-Hosani, 2018, Deaves et al., 2019, Evans, 2017, Yourechko, 2016, and created the motivational survey. This motivational survey consisted of two parts. The first part encompassed the demographic information for participants. The second part consisted of 28 multiple choices items that were divided equally into four different dimensions. These four dimensions were: (a) self-efficacy, (b) expectancy, (c) intrinsic motivation, and (d) mathematics learning value. The survey used a fourpoint Like scale ranging from 1 (strongly disagree) to 4 (strongly agree). In addition, the instrument was assessed by four experts in the mathematics field for content 
validity and face validity. In order to evaluate the reliability of this instrument, before it was used in the study, the motivational survey was administered to 30 12th grade students of in Abha. The Cronbach's alpha reliability co-efficient was 0.86 . This indicated the survey has an acceptable degree of reliability.

\section{Data collection}

Operational procedures. This study was first given to participants by the Study assistant during the last week of November, 2019, and was completed three weeks later. Two sources of data were used in this study, which were the probability and statistics pre/posttest and pre/post motivational survey. Both of these instruments were constructed by the Studyer specifically in order to measure the academic achievement and motivational learning with regards to statistics and probability in this study. Following the probability and statistics pre-test, participants were given the survey in which they were asked to rate their level of motivation toward learning statistics and probability. On the following day, the experimental group received an introductory session about how to use Twitter. This session was conducted in the computer lab of the school, while students in the control group received their lessons in their regular classroom. A twitter account was created of each participant. The Twitter accounts were tobe used in learning probability and statistics unit, and to facilitate communication between the teacher and students. In addition, an email group was created for the teachers to facilitate communication between the Studyer and the experimental teacher groups. The experimental phase took place during a three-week period during November and December of 2019. At the conclusion of the treatment, both the experimental and control groups participated in the post-test during single 45minute sessions. The administration of the post-test was identical to the 16 -item pretest that was given prior to the treatment period. The probability and statistics test was administered to both groups at the beginning and at the end of the study in order to measure the effect of the treat- ment. This test was scored by the Studyer, Study assistant, and teacher who were participating in the study. This was done to help minimize experimenter effects and/or Studyer bias.

\section{Descriptive statistics}

Descriptive statistics and Cronbach's alpha for the major study variables are shown in Table 2. Per Nunnally and Bernstein (1994), a measure is moderately reliable if its Cronbach's alpha if .70. The findings in Table 3 reveal that the pretest attitude measure was not reliable; the posttest attitude measure, however, was reliable.

Table 3

Descriptive Statistics for the Study Variables

\begin{tabular}{lrrrrr}
\hline \multicolumn{1}{c}{ Variables } & $N$ & $\alpha$ & Range & $M$ & \multicolumn{1}{c}{$S D$} \\
\hline & & & & & \\
Math test & & & & & \\
$\quad$ Pretest & 48 & -- & 0 to 11 & 3.80 & 2.61 \\
$\quad$ Posttest & 48 & -- & 9 to 16 & 13.69 & 1.73 \\
Math motiva- & & & & & \\
$\quad$ tions & 24 & .45 & 0 to 1 & .89 & .11 \\
Pretest & 24 & .85 & 2 to 3 & 2.86 & .25 \\
$\quad$ Posttest & & & & & \\
\hline
\end{tabular}

\section{Results of the hypothesis tests}

It was hypothesized that learning in a flipped classroom via Twitter, versus learning in a traditional classroom, would lead to an improvement in math performance (H1). It was further hypothesized that learning in a flipped classroom via Twitter would lead to an improvement in math performance but that this improvement within the flipped classroom (versus non-improvement in the traditional classroom) would differ across gender (H2). To test these hypotheses, a $2 \times 2 \times 2$ mixed ANOVA procedure was conducted. The within-subjects variable was time (i.e., pretest vs. posttest), the first between-subjects variable was type of classroom (i.e., traditional vs. flipped), and the second between-subjects variable was gender (i.e., male vs. female). To determine whether learning in a flipped classroom via Twitter would lead to an improvement in math performance (H1), the two-way interaction effect was evaluated using a p-value of 05 . To determine whether gender would moderate improvement within the Twitter classroom (vs. the traditional classroom; $\mathrm{H} 2$ ), the three-way interaction effect was evaluated using a p-value of .05 . 
The means and standard deviations for math performance within males, within females, and with the whole sample are shown in Table 4; the $2 \times 2 \times 2$ mixedANOVA results are summarized in Table 5. Math performance improved significantly across time (see Table 5); the mean posttest score (regardless of gender and classroom) was significantly higher than the mean posttest score (see Table 4). But this improvement in time did not differ as a function of type of classroom (see Table 5). The findings in Table 4 and in Figure 1 show that improvement was the same across types of classroom. As such, the first hypothesis was not supported. Further, this improvement in time did not differ as a function of type of classroom and across gender (see Table 5). As shown in Table 4 and depicted in Figure 1, within the sample of male students, scores changed across time, regardless of classroom. Similarly, within the sample of female students, scores also changed across time, regardless of classroom. The pattern of change across time was the same for males and females. Therefore, the second hypothesis was not supported.

Table 4

Descriptive Statistics for Math Performance across Time within Gender as a Function of Type of Classroom $(\mathrm{N}=48)$

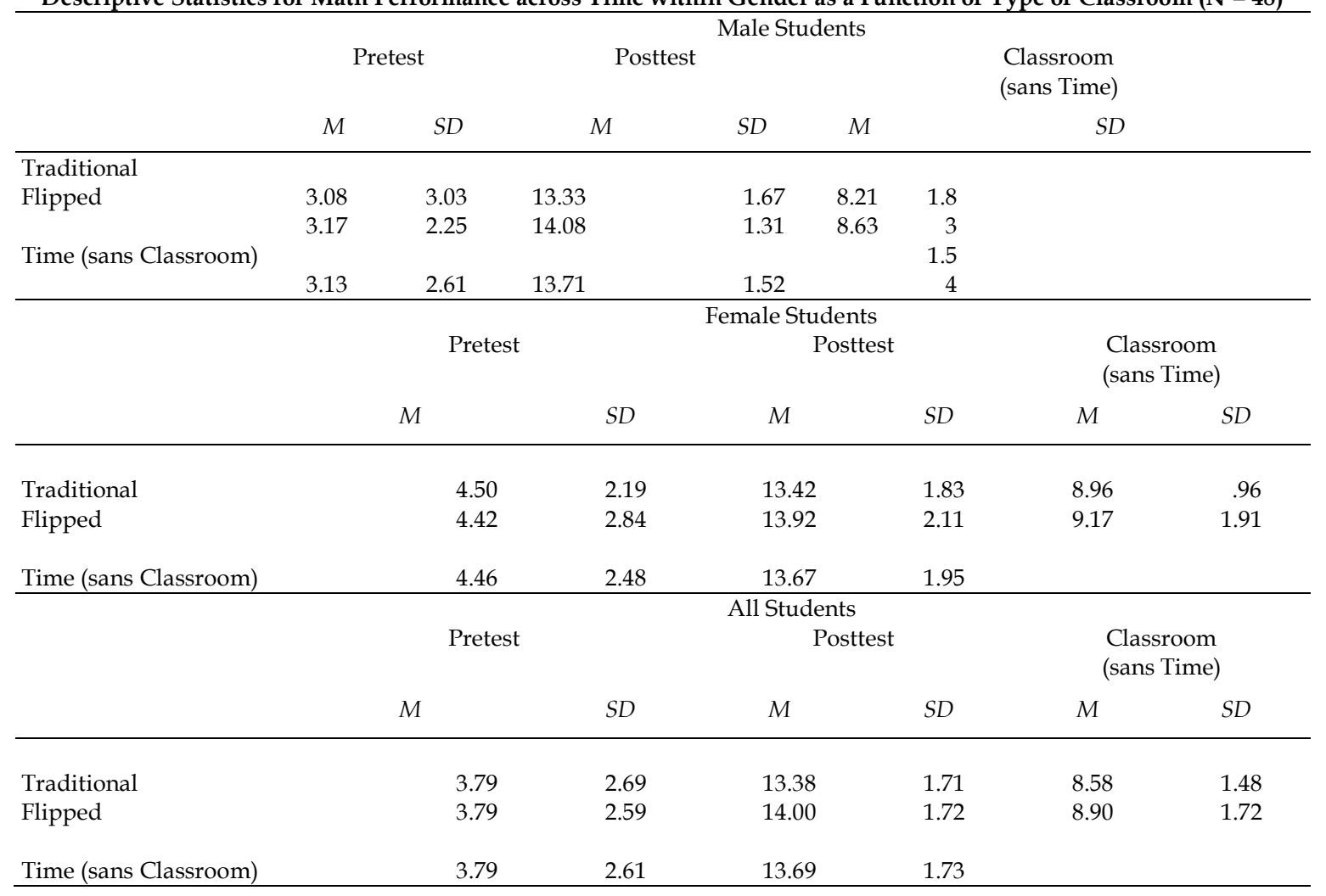



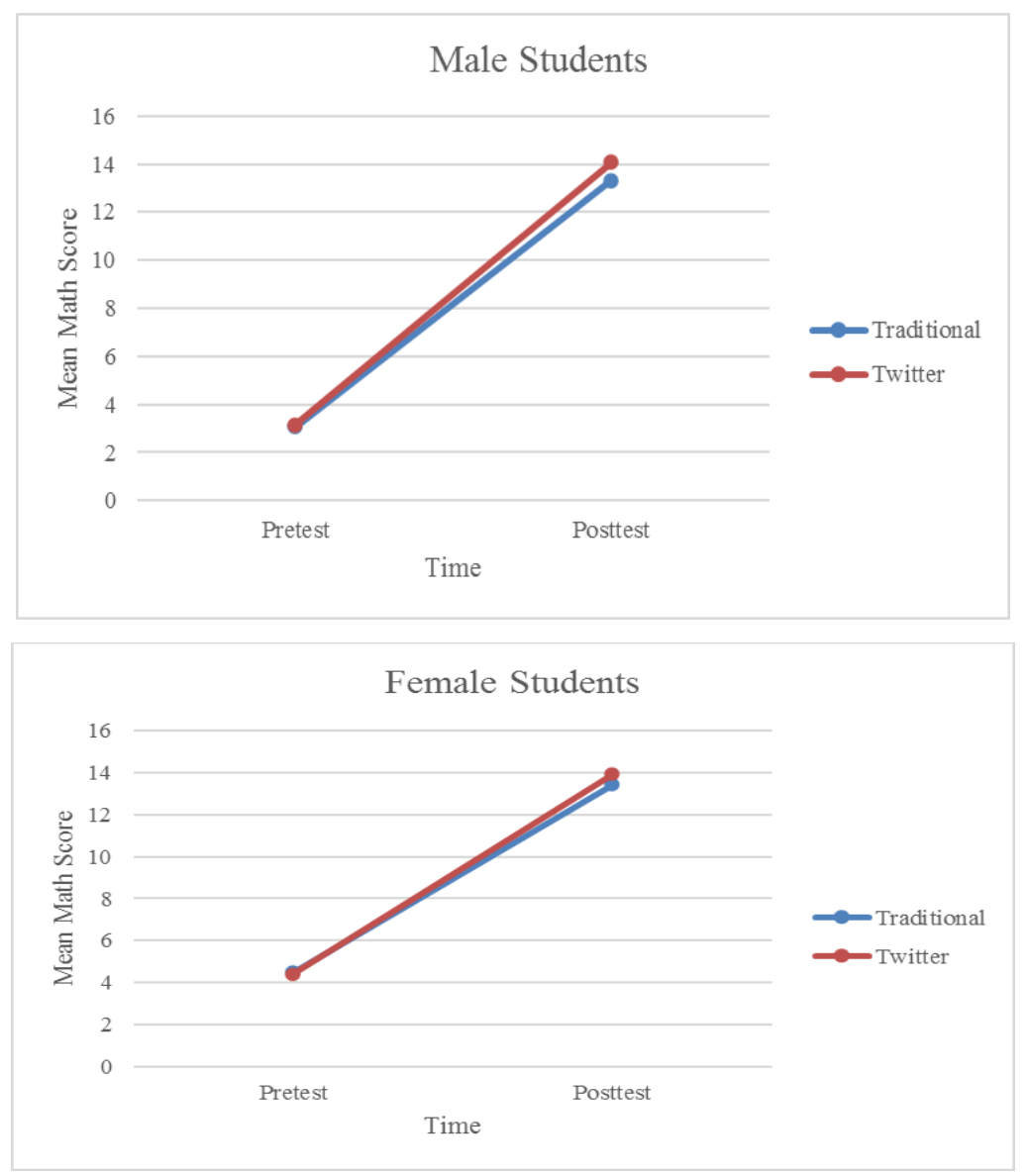

Figure 1. Male and female students' math scores from pretest to posttest as a function of classroom.

Table 5

Mixed ANOVA Results for Math Performance across Time within Gender as a Function of Type of Classroom $(\mathrm{N}=48)$

\begin{tabular}{|c|c|c|c|}
\hline \multicolumn{4}{|c|}{ Function of Type of Classroom $(N=48)$} \\
\hline Source & $d f$ & $M S$ & $F$ \\
\hline \multicolumn{4}{|l|}{ Between subjects } \\
\hline Type of classroom & 1 & 2.34 & .46 \\
\hline Gender & 1 & 10.01 & 1.95 \\
\hline Type of classroom $x$ gender & 1 & .26 & .05 \\
\hline Error & 1 & 5.15 & \\
\hline Within subjects & 44 & & \\
\hline Time & & 2350.26 & $498.27^{* * *}$ \\
\hline Time $x$ type of classroom & 1 & 2.34 & .50 \\
\hline Time $\mathrm{x}$ gender & 1 & 11.34 & 2.41 \\
\hline Time $x$ type of classroom $x$ gender & 1 & .01 & .00 \\
\hline \multirow[t]{2}{*}{ Error } & 1 & 4.71 & \\
\hline & 44 & & \\
\hline
\end{tabular}

${ }^{*} p<.05 .{ }^{* *} p<.01 .{ }^{* * *} p<.001$.

It was hypothesized that learning in a flipped classroom would lead to more positive attitudes towards mathematics (H3). It was further hypothesized that learning in a flipped classroom via Twitter would lead to more positive attitudes towards mathematics but that this improvement within the flipped classroom would differ across gender (H4). To test these hypotheses, a $2 \times 2$ mixed ANOVA procedure was conducted. The withinsubjects variable was time (i.e., pretest vs. posttest) and the between-subjects variable was gender (i.e., male vs. female). To determine whether learning would lead to more positive attitudes towards mathematics, the main effect of time was evaluated using a p-value of .05 (H3). To deter- 
mine whether gender would moderate improvement within the Twitter classroom, the two-way interaction effect was evaluated using a p-value of .05 (H4).

Attitudes towards math changed significantly across time (see Table 7). Students assigned to the flipped classroom had more positive attitudes towards math after the intervention than prior to the intervention (see Table 6). Thus, the third hypothesis was supported. Attitudes towards math also differed across males and females (see Table 7). Regardless of time, females had significantly more positive attitudes towards math than males. More importantly, however, the positive trend differed across males and females (see Table 7). As shown in Figure 2, the positive change in attitudes was greater for females (i.e., the difference from pretest to posttest was 1.91), than it was for males (i.e., the difference from pretest to posttest was 1.48). Therefore, the fourth hypothesis was supported.

Table 6

Descriptive Statistics for Math Performance across Time as a Function of Gender $(\mathbf{N}=24)$

\begin{tabular}{lcccc}
\hline & \multicolumn{2}{c}{ Time as a Function of Gender $(\mathbf{N}=\mathbf{2 4})$} \\
\hline \multicolumn{1}{c}{ Pender } & $M$ & $S D$ & $M$ & $S D$ \\
\hline Male & .75 & .10 & 2.23 & .12 \\
Female & .75 & .12 & 2.66 & .10 \\
\hline
\end{tabular}

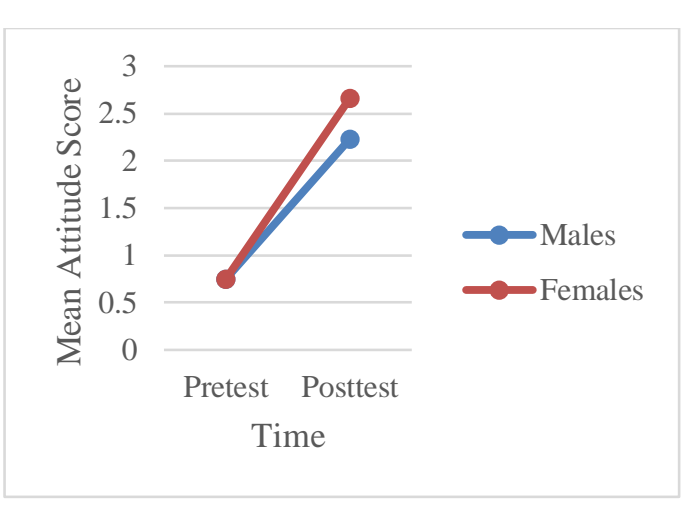

Figure 2. Attitudes toward math from pretest to posttest for males and females.

Table 7

Mixed ANOVA Results for Math Attitudes across Time as a Function of Gender $(\mathbf{N}=\mathbf{2 4})$

\begin{tabular}{|c|c|c|c|}
\hline Source & $d f$ & $M S$ & $F$ \\
\hline \multicolumn{4}{|l|}{ Between subjects } \\
\hline Gender & 1 & & \\
\hline Error & 22 & .56 & $51.32^{* * *}$ \\
\hline Within subjects & & .01 & \\
\hline Time & & & \\
\hline Time $x$ Gender & 1 & 34.47 & 2509.33 *** \\
\hline \multirow[t]{2}{*}{ Error } & 1 & .54 & $39.55 * *$ \\
\hline & 22 & .01 & \\
\hline
\end{tabular}

\section{Discussion}

The primary objective of the study was to determine whether the Twitter, when used in association with a flipped classroom, would increase the academic achievement and/or learning motivation toward mathematics for 12th grade students. The secondary objective was to determine whether there were differences in the academic achievement and learning motivation between male and female students when using the Twitter in association with a flipped classroom. In line with these objectives, male and female students were assigned to one of two groups (i.e., traditional math instruction only vs. flipped classroom math instruction by using Twitter) and tested prior to and after treatment.

The findings did not support the first and second hypotheses: Twitter, when used as in the context of a flipped classroom method, did not improve academic achievement. Improvement in academic achievement from pretest to posttest also did not differ across gender. However, the results did support the third hypothesis: Within the flipped classroom that included Twitter use, the improvement in motivation was stronger for girls than it was for boys.

\section{Interpretation of Findings}

The findings of the current study that using Twitter within the context of a flipped classroom did not lead to improvement in academic achievement corroborates the findings of Vilchec (2016). Vilchec (2016) demonstrated that using Twitter in the learning environment did not increase the academic achievement for $9^{\text {th }}$ grade students in Algebra 1, specifically in the linear equations unit. However, the current findings run counter to that of Blessing, et al. (2012) and Junco, et al. (2010), for the findings of these Studyers indicated that using Twitter did lead to an increase the level of academic achievement for students. There seem to be two possible reasons for the discrepancy in findings. These interpretations have to do with the difficulty of the subject matter and implementation of the four main pillars of the flipped classroom (Hamdan, et al., 2013). 
Twitter may lead to improvement when the subject matter is relatively easy (per Blessing, et al., 2012 and Junco, et al., 2010) and when all four pillars of the flipped classroom are implemented: (a) flexible learning environment that allows teachers to reorganize the classroom as needed; (b) a learning culture that lets students be the center of learning and producers of knowledge; (c) intentional content that is defined by teachers and discovered by students: and (d) a professional educator who has possesses well-developed professional skills in the use of the flipped classroom method.

The findings of this current study which showed that using Twitter within the context of a flipped classroom led to an improvement in academic achievement corroborates the findings of Vilchez (2016). Vilchez demonstrated that although using Twitter in the learning environment did not increase the academic achievement for 9th grade students in Algebra 1, it did lead to an improvement in motivation. Whether the improvement in motivation was due to self-efficacy, expectancy, intrinsic motivation, mathematics learning value (i.e., the subscales of the current study's motivation measure), or some other factor remains unclear, for definition of motivation used by Vilchec was not specified.

\section{Study limitations}

One limitation of the current study is that the pretest survey was not reliable. Because of this, the main study finding that improvement in motivation was steeper for those in the flipped Twitter classroom is also not reliable.

A second limitation is that the design of the flipped Twitter classroom was not mapped onto the four pillars of the flipped classroom. As such, it was difficult to determine why the intervention did not lead to an improvement in academic achievement.

\section{Recommendations}

Future studies involving flipped classrooms will need to take into consideration the four major pillars of the flipped classroom approach. Classes will need to be mapped onto these four pillars, and specific predictions must be tied to these micro-relationships. Specific aspects of motivation should also be linked to the four pillars. Furthermore, to make comparisons across studies more meaningful, the difficulty of subject matter must also be objectively measured. If this were to be done, it would be possible to formulate explanations for contradictory or corroborating evidence.

\section{References}

Abdurabb, T. K. (2014). Saudi Arabia has highest number of active Twitter users in the Arab world. Arab News. Retrieved from http://www.arabnews.com/news/59 2901

Abo Galbh, M. (2015). The Effect of Flipped Classroom by Using Edmodo Website to Enhance Creative Thinking and Attitudes toward Biology Course in High School in Riyadh. (Master Thesis, IMSI University). Saudi Arabia.

Aldaosary, F., \& Al-masaad, A. (2017). Impact of Flipped Classroom on Academic Achievement of Programming Learning in Computer Course for 10th grade students. International Journal of Educational Study, 41(3), 138-164.

Alhamadi, A. (2017). The influence of social media on Saudi graduate students: An explanatory case study of six Saudi graduate students studying in American universities (Doctoral dissertation, Kansas State University). Retrieved from https:// krex.kstate.edu/dspace/bitstr eam/handle/2097/38211/AsmaAlha madi2017.pdf?sequence $=3$.

Al-harbi, Fawzia. (2017). The effectiveness of using the inverted learning strategy in developing self-learning skills and organizing the enrichment environment from the point of view of gifted students. Journal of Special Education and Rehabilitation, 4(16), 115-152.

Almankory, A. (2019). To what extent do university students in Saudi Arabia find a social media tool (Twitter) use- 
ful in their respective learning environments? (Doctoral dissertation, Durham University). Retrieved from http:/ / etheses.dur.ac.uk/13249/1/Al mankory_corrected_thesis.pdf

Ambusaidi, A. \& Al-Hosani, H. (2018). The Impact of Flipped Classroom Approach in Acquiring Motivation towards Science Learning and Academic Achievements on Ninth-Grade Female Students. Humanities Journal, 32(8), 1570-1604.

Anderson, S. (2011). The Twitter toolbox for educators. Teacher Librarian, 39, 2730.

Archambault, L., Wetzel, K., Foulger, T. S., \& Williams, M. K. (2010). Professional Development 2.0: Transforming Teacher Education Pedagogy with 21st Century Tools. Journal of Digital Learning in Teacher Education, 27, 4-11.

Asiri, A. (2018). Mathematics Olympiad competencies in textbooks: analyzing the content of secondary school mathematics books in light of the basic competencies of the Mathematics Olympiad competition. Obeikan Company, Riadh.

Batanero, C. \& Borovcnik, M. (2016). Statistics and probability in high school. Rotterdam: Sense Publishers.

Batanero, C., \& Díaz, C. (2012). Training teachers to teach probability: Reflections and challenges. Chilean Journal of Statistics, 3(1), 3-13.

Bergmann, J., \& Sams, A. (2012). Flip Your Classroom: Reach Every Student in Every Class Every Day (pp. 120-190). Washington DC: International Society for Technology in Education.

Blessing, S., Blessing, J., \& Fleck, B. (2012). Using Twitter to reinforce classroom concepts. Teaching of Psychology, 39(4), 268-271. doi:10.1177/009862831246 1484

Buzzelli, A. A., Holdan, G., Lias, A. R., Rota, D. R., \& Evans, T. Z. (2019). Rethinking Twitter: Unique Characteristics of Twitter Render It an Instructional Asset. In M. Habib (Ed.), Advanced Online Education and Training Technologies (pp. 163-184). Hershey,
PA: IGI Global. doi:10.4018/978-15225-7010-3.ch010

Campbell, D. T., \& Stanley, J. C. (1963). Experimental and quasi-experimental designs for Study. Chicago: Rand McNally.

Carnell, L. (2008). The effect of a studentdesigned data collection project on attitudes toward statistics. Journal of Statistics Education, 16(1). Retrieved from: http://jse.amstat.org/v16n1/carnell.h tml

Carpenter, J. P., \& Krutka, D. G. (2014). How and why educators use Twitter: A survey of the field. Journal of Study on Technology in Education, 46(4), 414434. doi:10.1080/1539123.2014.925701

Deaves, A., Grant, E., Trainor, K., \& Jarvis, K. (2019). Students' perceptions of the educational value of Twitter: a mixedmethods investigation. Study in Learning Technology, 27. https://doi.org/10.25304/rlt.v27.2139

Draper, J. A., Buzzelli, A. A., \& Holden, E. G. (2016). The pattern of use of Twitter in one accelerated, cohort-based doctoral based program. International Journal of Doctoral Studies, 11, 163-183. Retrieved from http://www.informingscience.org/ Publications/3453

Dunlap, J. C., \& Lowenthal, P. R. (2009). Tweeting the night away: Using Twitter to enhance social presence. Journal of Information Systems Education, 20, 129-135.

El Mourad, H. (2014). The Saudis are at the forefront among social media users. Arabian Business.com. Retrieved from

http://arabic.arabianbusiness.com/te chnology/2014/jun/19/364372/

Evans, TZ. (2017). Twitter in the Higher Education Classroom: Exploring Perceptions of Engagement. (Doctoral Dissertation). USA: Robert Morris University

Fredricks, J., McColskey, W., Meli, J., Mordica, J., Montrosse, B., \& Mooney, K. (2011). Measuring student engagement in upper elementary through high school: A description of 21 in- 
struments. Issues $\mathcal{E}$ Answers Report, REL, $\quad 098 . \quad$ Retrieved from http://ies.ed.gov/ncee/edlabs

Fox, B. I., \& Varadarajan, R. (2011). Use of Twitter to encourage interaction in a multi- campus pharmacy management course. American Journal of Pharmaceutical Education, 75(5), 1-8.

Fulton, K. (2012). Upside down and inside out: Flip your classroom to improve student learning. Learning $\mathcal{E}$ Leading with Technology, 39(8), 12-17.

Galagan, P. (2009). Twitter as a learning tool. Really. $T+D, 28-31$.

Gall, M. D., Gall, J. P., \& Borg, W. R. (2006). Educational Study: An introduction (8th ed.). Boston: Allyn and Bacon.

Gao, F., Luo, T., \& Zhang, K. (2012). Tweeting for learning: A critical analysis of Study on microblogging in education published in 2008-2011. British Journal of Educational Technology, 43, 783-801. doi:10.1111/j.14678535.2012.01357.x

Global Media Insight (GMI), (2018). Saudi Arabia Social Media Statistics 2018. Retrieved from https://www.globalmediainsight.com /blog/saudi-arabia-social-mediastatistics /

Hamdan, N., McKnight, P., McKnight, K., \& Arfstrom, K. (2013). A review of flipped learning. Retrieved from: http://flippedlearning.org/cms/lib07 /VA01923112/

Harris, A. L., \& Rea, A. (2009). Web 2.0 and virtual world technologies: A growing impact on IS education. Journal of Information Systems Education, 20(2), 137-144.

Jacob, Bridgette. (2013). The Development of Introductory Statistics Students' Informal Inferential Reasoning and Its Relationship to Formal Inferential Reasoning. Unpublished Thesis Dissertation, Syracuse University.

Jones, G. (2005). Introduction. In G. Jones (Ed.), Exploring probability in school: challenges for teaching and learning (pp. 1-12). New York: Springer.

Junco, R., Elavsky, C. M., \& Heiberger, G. (2012). Putting Twitter to the test: Assessing outcomes for student collaboration, engagement, and success. British Journal of Educational Technology, 44, 273-287. doi:10.1111/j.14678535.2012.01284.x

Junco, R., Heiberger, G., \& Loken, E. (2010). The effect of Twitter on college student engagement and grades. Journal of Computer Assisted Learning. doi:10.1111/j.1365-2729.2010.00387.x

Kaplan, A. M., \& Haenlein, M. (2010). Users of the world, unite! The challenges and opportunities of Social Media. Business Horizons, 53. 59-68. doi:10.1016/ j.bushor.2009.09.003

Ministry of Education (2019). Schools' database. Retrieved from https://www.moe.gov.sa/Arabic/ES ervices/Public/Pages/SchoolProfile.a spx?qsId $=47255$

Minocha, S., Schroeder, A., \& Schneider, C. (2010). Role of the educator in social software initiatives in further and higher education: A conceptualisation and Study agenda. British Journal of Educational Technology, 42(6), 889-903. doi:10.1111/j.1467 8535.2010.01131.x

Mohammed, M. (2012). Effectiveness of applications of potential distributions in the development of problem solving and decision-making among 12th grade students. Knowledgeable and reading journal, 133, 139-152.

National Center for Assessment, (2019). Report of Students Results in Annual Test. Retrieved from: https://etec.gov.sa/ar/Studyers/Pag es/OpenData.aspx

Nicholson, J., \& Galguera, T. (2013). Integrating new literacies in higher education: A self-study of the use of Twitter in an education course. Teacher Education Quarterly, 40(3), 7-26.

Nunnally, J. C. \& Bernstein, I.H. (1994). Psychometric theory. New York: McGraw-Hill. 
Ozofor, N. (2015). Effects of two modes of Computer Aided Instruction on students' achievement and interest in mathematics. International Journal of Education and Study, 3(1), 89-102.

Pearson. (2013). Flipped learning in higher education. Retrieved from: http:/ / flippedlearning.org/wpcontent/uploads/2016/07/HigherEdWhi tePaper-FINAL.pdf.

Pyhältö, K., Toom, A., Stubb, J., \& Lonka, K. (2012). Challenges of becoming a scholar: A study of doctoral students' problems and well-being. International Scholarly Study Network Education, 12, 1-12. doi:10.5402/2012/934941

Schroeder, A., Minocha, S., \& Schneider, C. (2010). The strengths, weaknesses, opportunities and threats of using social software in higher and further education teaching and learning. Journal of Computer Assisted Learning, 26(3), 159-174. doi:10.1111/j.13652729.2010.00347.x

Stone, B. (2012): “Flip Your Classroom to Active Learning and Student Engagement". Paper Presented at 28th Annual Conference on Distance Teaching \& Learning. The Board of Regents the University of Wisconsin System, USA.

Unakorn, P., \& Klongkratoke, U. (2015). Effectiveness of flipped classroom to mathematics learning of grade 11 students. A Paper presented at the 21st \& 22nd International Conference on Language, Education, and Humanities \& Innovation. Retrieved from https://icsai.org/procarch/1iclehi/1i clehi-44.pdf

Van Vooren, C., \& Bess, C. (2013). Teacher tweets improve achievement for eighth grade science students. Journal of Systemics, Cybernetics and Informatics, 11(1), 33-36.

Vilchez, Manuel. (2016). An Investigation of the Effect of Using Twitter by High School Mathematics Students Learning Linear Equations in Algebra 1. (Doctoral Dissertation). USA: Florida International University.
Vohra, S. (2016). How social presence on Twitter impacts student engagement and learning in a grade 8 mathematics classroom. Walden University. Retrieved from

https://scholarworks.waldenu.edu/d issertations/2430/

Wei, C., Chen, N., \& Kinshuk. (2012). A model for social presence in online classrooms. Educational Technology Study \& Development, 60(3), 529-545. doi:10.1007/s11423-012-9234-9

Yakin, I., \& Tinmaz, H. (2013). Using twitter as an instructional tool: A case study in higher education. The Turkish Online Journal of Educational Technolo$g y, 12(4), 209-218$.

Yarbro, J., Arfstrom, K. M., McKnight, K., \& McKnight, P. (2014). Extension of a review of flipped learning. Retrieved from:

http://flippedlearning.org/cms/lib07 /VA01923112/Centricity/Domain/41 /Extension\%20of\%20Flipped \%20Lear ning\%20Lit\%20Review\%20June\%2020 14.pdf

Yourechko, A. (2016). The effect of Twitter on secondary student engagement and academic performance. (Doctoral dissertation). Retrieved from: http://www.proquest.com/enUS/products/dissertations/individua ls.shtml.

Zickuhr, K., \& Rainie, L. (2014). Younger Americans' reading habits and technology use. Retrieved from http:/ / www.pewinternet.org/2014/0 9/10/younger-americans-readinghabits-and-technology-use/ 